\title{
Detecting of gas zones in khatatba formation, qasr field, western desert, Egypt
}

\begin{abstract}
The nature of fluids and permeability can be detected by using the Repeat Formation Tester (RFT) data. This detection is applied on Khatatba Formation by using six wells in Qasr Field in the Western Desert of Egypt. The Schlumberger Repeat Formation Tester (RFT) is an openhole wire line device showing a continuous recording of the pressure leads to construct the pressure gradient. The fluid density and then the nature of fluids (gas, oil and water) are determined by measuring these gradients. The main objective of this research is to show the oil water contact within the zone of interest. The abrupt change in the pressure gradients the depths of contacts between water and hydrocarbon products can be located. Qualitative and quantitative permeability's of Khatatba Formation are evaluated by the direct interpretation of the pressure curve recorded at each test and by the analysis of drawdown pressure data.
\end{abstract}

Volume 3 Issue 5 - 2018

\author{
Ahmed Nooh, Tarek F Shazly, MA Ramadan, \\ M Sawy \\ Department of Petroleum, Egyptian Petroleum Research \\ Institute, Cairo, Egypt
}

Correspondence: Ahmed Nooh, Department of Petroleum, Egyptian Petroleum Research Institute, Ahmed El Zomor St, Nasr city, Cairo, Egypt, Tel 00201003976340 , Email alannooh@hotmail.com

Received: May 30, 2018 | Published: November 01, 2018

Keywords: gas, permeability, fluids, resolution, digital, scales, million, continental, margin

\section{Introduction}

Some of reservoir characteristics such as the nature of fluids and permeability are important parameters. One of the most important tools which is the Repeat Formation Tester (RFT) can determine these parameters. The RFT tool is a wire line formation tester that can be set any number of times during a single trip in the well. For depth control, Gamma ray or sp curves are used. These pressure data are recorded at the surface on both analog and high resolution digital scales. ${ }^{1}$ The pretest fluid samples are not saved. However, after a successful pretest in a zone of interest, a larger fluid sample can be taken and retained. In one trip, a segregated fluid sample can be recovered from one test depth or two samples can be recovered from different depths. ${ }^{2}$ Determination of the nature of fluid, permeability's and depth of contact are applied on Khatatba Formation for six wells located in Qasr Field in the Western Desert of Egypt. The studied wells are Qasr-1x, Qasr-2x, Qasr-3x, Qasr-4x, Qasr-5x and Qasr-6x as shown in Figure 1.

\section{Geological background}

In Egypt, Western Desert province is one of the most promising oil and gas producing areas. In 2003, Qasr Field is discovered and is considered one of the huge gas fields in Western Desert, with production rates of $670 \mathrm{MMcfd}$ and 30 million barrels of condensate. The studied area belongs to the Eastern Shushan Basin, ${ }^{3}$ which is about $50 \mathrm{~km}$ south of the Mediterranean coast, between Latitudes $30^{\circ} 36^{\prime}$ and $30^{\circ} 39^{\prime} \mathrm{N}$ and Longitudes: $26^{\circ} 41^{\prime}$ and $26^{\circ} 44^{\prime} \mathrm{E}$, west of Qattara Depression. It covers about $455 \mathrm{~km} 2$ (Figure 1). According to the location of the studied area, it lies in the northern unstable shelf. ${ }^{4}$ The stratigraphic column of the Northern Western Desert and Shushan Basin in particular (Figure 2) is composed of alternating sequences of clastic-dominated intervals and carbonate intervals. ${ }^{5}$ The sedimentary cover of Western Desert is part of the foreland deposits which fringe the northern continental margin of the Afro-Arabian shield. In the northern Western Desert, the geologic history had been begun with the Early Paleozoic continental deposits. Two transgressions took place; the first one is over basement complex in the Cambro-Ordovician period with moderate relief while the second during Carboniferous time. ${ }^{6}$ Four unconformity-bound cycles, in the stratigraphy, can be marked; each one is terminated by a marine transgression. ${ }^{7}$ The earliest cycle consists of Early Jurassic non-marine siliciclastics (Ras Qattara Formation) which rest unconformably on the Silurian basement and which are overlain by the mid-Jurassic Wadi Natrun and Khatatba Formations. Shale and sandstones are the main composition of Khatatba Formation with coal seams and minor limestone's which more abundant north wards became. These sediments are interpreted to have been deposited in a deltaic environment.

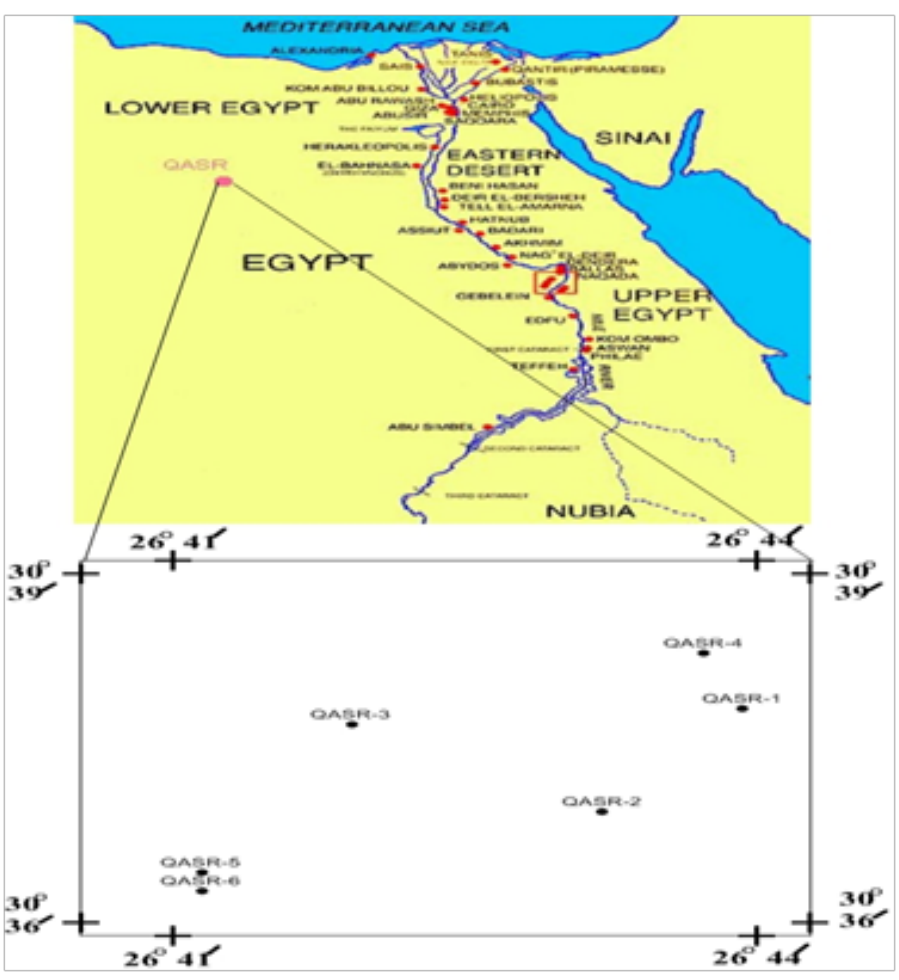

Figure I Location map of the study area. 


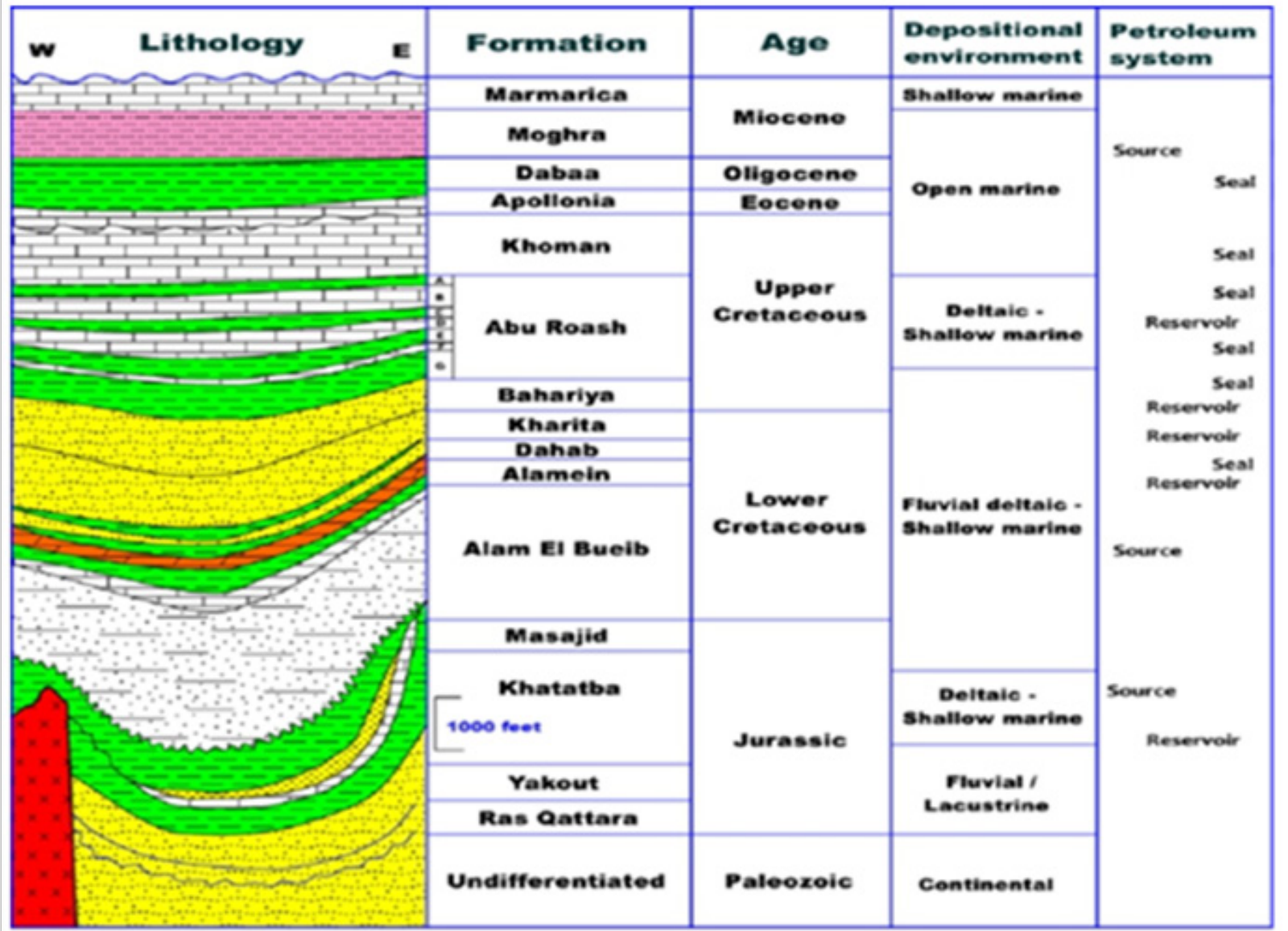

Figure 2 Simplified stratigraphic column of the Shushan basin. ${ }^{5}$

\section{Repeat formation tester (RFT)}

The Repeat Formation Tester can take an unlimited number of formation pressure measurements and up to two fluid samples in a single trip in open hole. To achieve a high degree of accuracy, the RFT tool makes use of advanced electronic circuitry and digital pressure readout. With special techniques and calibration against a dead-weight tester, an absolute accuracy of up to 13 psi for a 10,000psi gauge is achievable.

This capability of fast and accurate pressure measurement has opened up a new series of pressure measurement and a new series of reservoir analysis methods. The technique of point-by-point evaluation of reservoir pressure can evaluate reservoir pressure and can be used to determine pressure profiles, fluid density, fluid contacts, differential depletion and reservoir intercommunication. The drawdown and build-up pressure curves can provide measurement of effective permeability's in the invaded and in the uninvited zones. This technique is effective if, at the time of testing, the formation is still over pressured or supercharged by the invading mud filtrate. ${ }^{8}$

The Repeat Formation Tester uses an electrically driven hydraulic pump to provide pressure to operate its various systems. The hydraulic circuit is controlled from surface to provide repeated set-retract capability. In the tool, two sample chambers are available to take samples from two different zones, or to take a segregated sample from one zone. A strain gauge pressure transducer is located in the flow line to monitor pressure continuously during RFT test. Two pretest chambers of $10 \mathrm{cc}$ each are automatically opened after the tool is set to withdraw $20 \mathrm{cc}$ of fluid at two different rates (Figure 3).

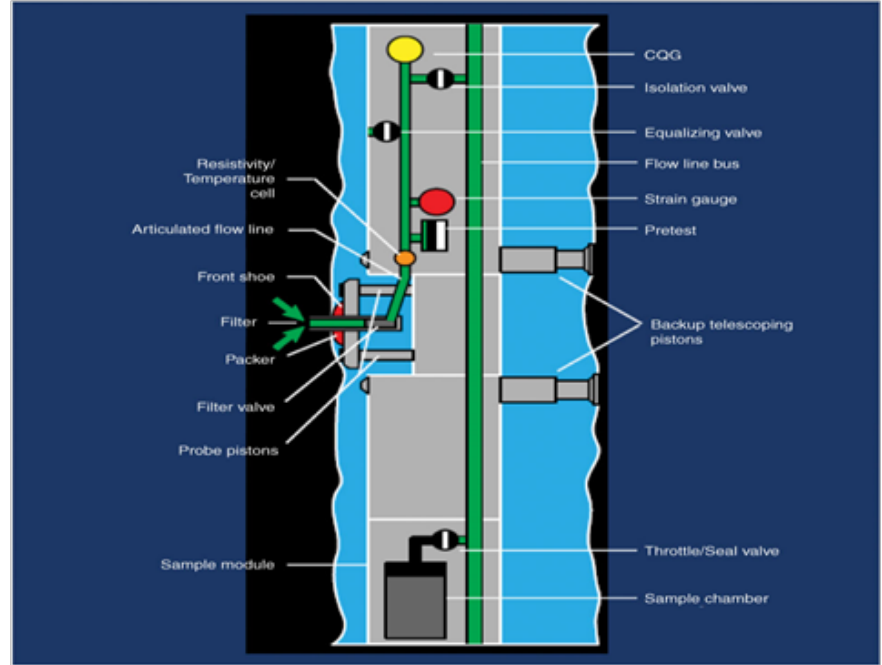

Figure 3 Schematic of RFT pretest and sampling system.

Pressure drawdown's during this period and the following buildup curve are recorded at the surface and provide data for permeability calculations and formation pressure. Several drawbacks are overcome by RFT tool than the other wire line testing systems. A packer moves out on one side, and back up pistons packer moves out on one side when the tool is set, thus the body of the tool is held away from the borehole wall to reduce the chances of differential sticking. A filter in the flow line probe prevents sand entry into the tool and the filter is cleaned by the piston when the tool is retracted. A pressure profile of a 
typical recording is shown in Figure 4. The analog pressure recording provides an excellent means of evaluating the integrity and general character of the pretest and the producibility of the formation. The pressure is initially at hydrostatic (mud) condition. When the piston stops, the pressure build up due to continued comparison of the packer, but suddenly drops again at the beginning of the pretest. At time t1, the piston in chamber No. 1 is fully withdrawn and the first pretest is completed. It is immediately followed by the higher flow rate and hence larger pressure drop of the second pretest. At time $t^{2}$, the piston in the second chamber is fully withdrawn and the pressure builds up to the formation pressure. ${ }^{9}$ beside the valuable information which can be gained, RFT tool also save rig time. ${ }^{10}$

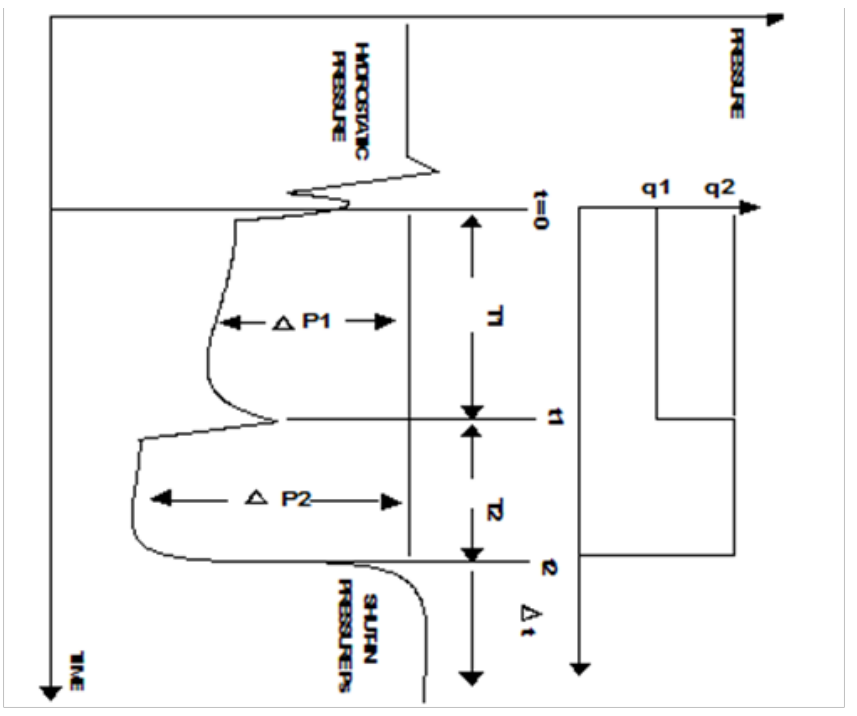

Figure 4 RFT analog pressure recording.

\section{Evaluation of density and nature of fluids}

The application of the Repeat Formation tester in this study is the determination of reservoir pressure, fluid density and fluid contact. The different measured formation pressure opposite the reservoir is plotted against the depth, and from this plot the nature of the flowing fluids (oil, gas or water) can be identified from their gradients. The continuous phase is water if the analyzed gradient give the value of density of, while if the measured densities are that of oil or gas, then the continuous phase will be oil or gas. ${ }^{11}$

The depth of free water level can be estimated by studying the abrupt change in pressure on the pressure gradient. The pressure readings when plotted versus depth will normally produce gradients with pressures increasing with depth in which the slope of a particular gradient (extrapolated line) is related to fluid density within the reservoir. The relationship between fluid density and the pressure gradient can be expressed by the following equations:

Fluid density $\left(\mathrm{g} / \mathrm{cm}^{3}\right)=2.31 *$ pressure gradient

In which:

$$
\text { pressure gradient }=\frac{1}{m}=\frac{\text { pressure in Psi }}{\text { depth in } f t}
$$

Where: $\mathrm{m}$ is the slope of the extrapolated line.

Also, the free water level is represented by the intersection of the water gradient with the oil or gas gradient. The formation pressure against the depth, for Khatatba Formation in Qasr-1x, Qasr-2x, Qasr3x, Qasr-4x, Qasr-5x and Qasr-6x wells are shown in Figures 5-10.

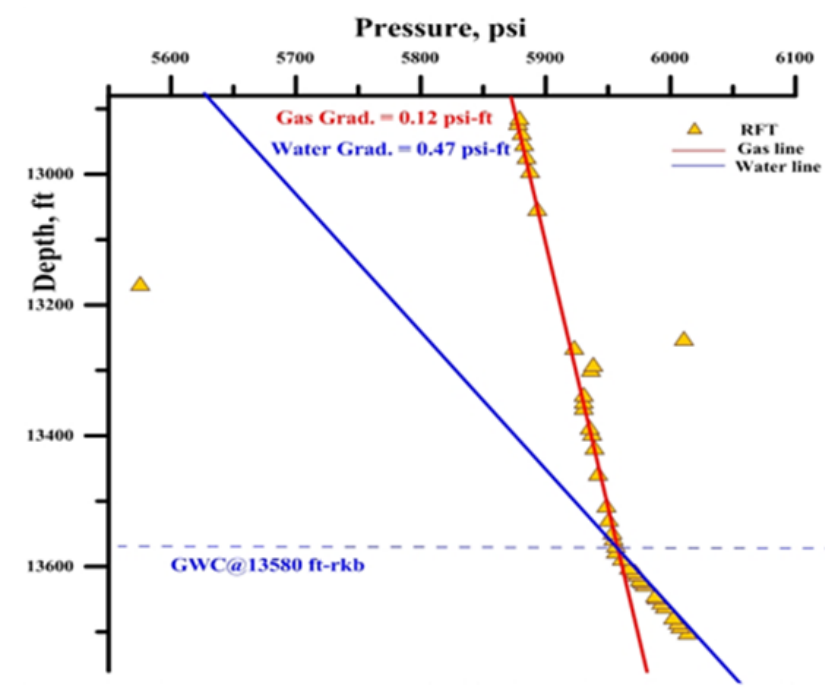

Figure 5 Khatatba Formation in Qasr-Ix well.

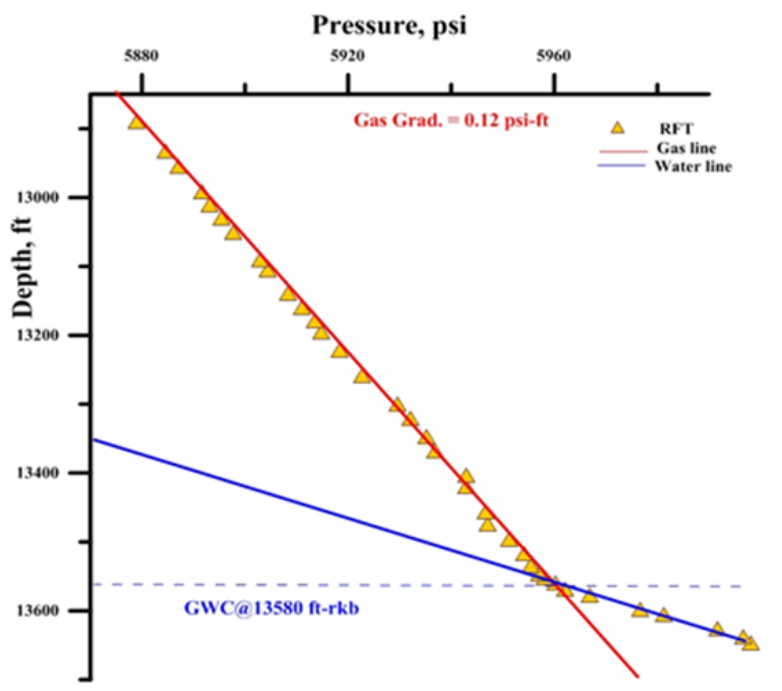

Figure 6 Khatatba Formation in Qasr-2x well.

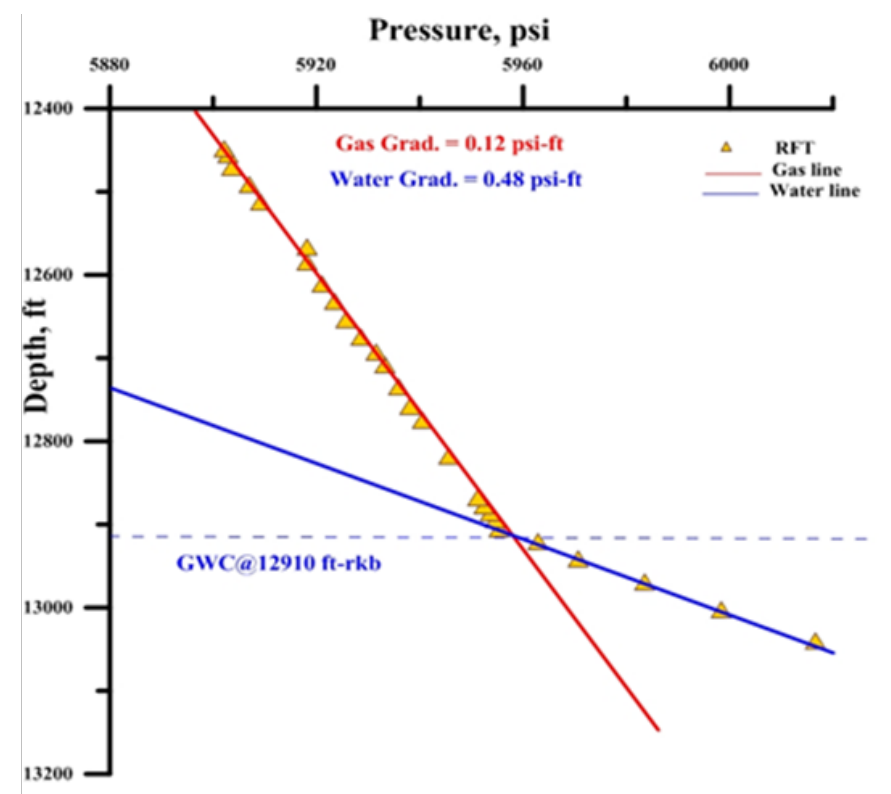

Figure 7 Khatatba Formation in Qasr-3x well. 


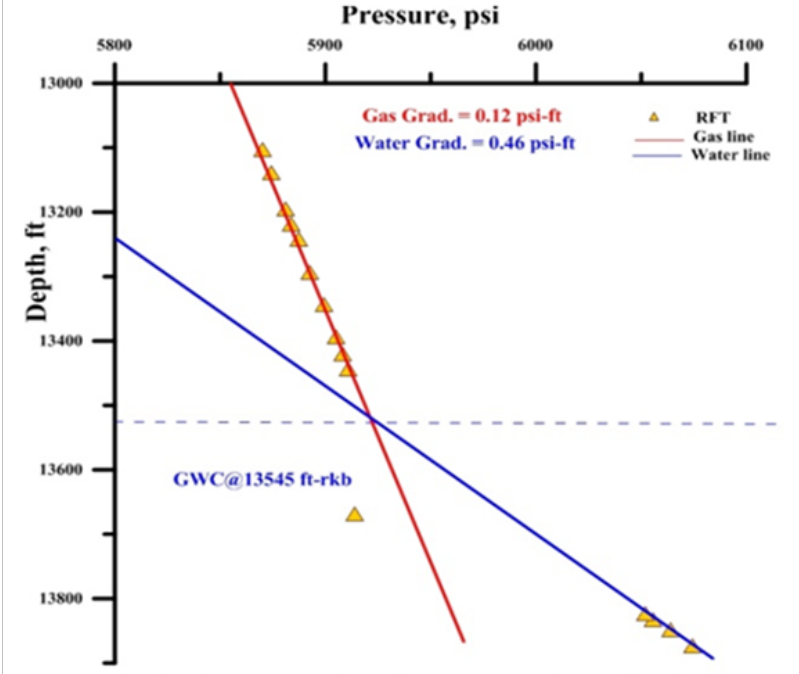

Figure 8 Khatatba Formation in Qasr-4x well.

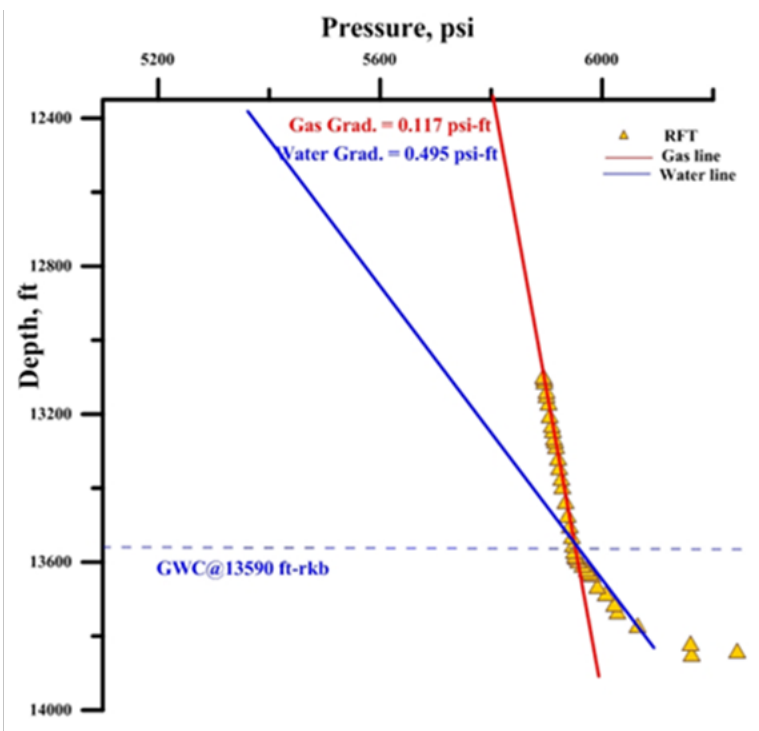

Figure 9 Khatatba Formation in Qasr-5x well.

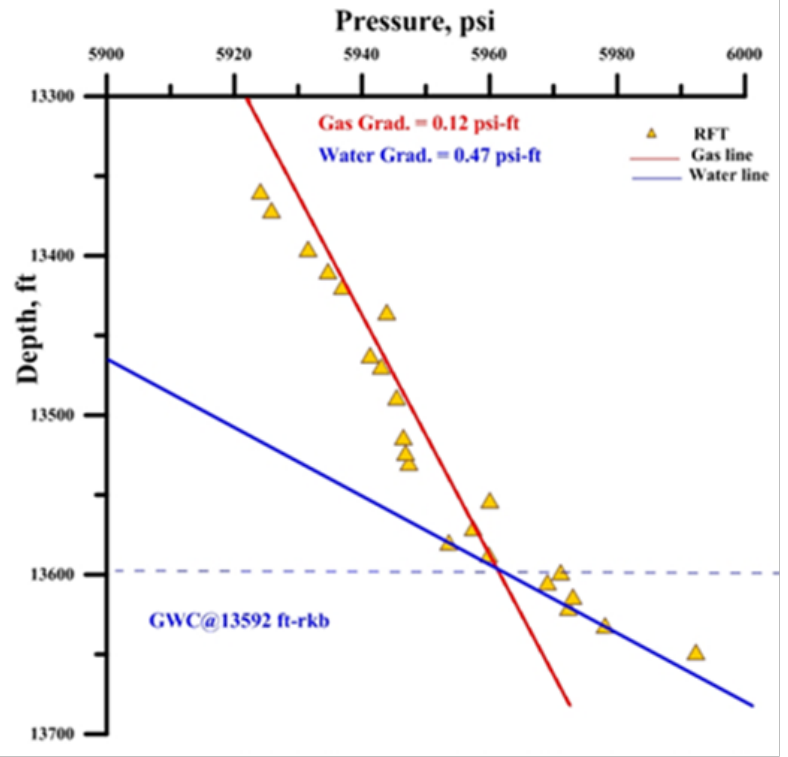

Figure 10 Khatatba Formation in Qasr-6x well.
The pressure profile clearly indicates two distinct trends in the considered wells. The first gradient represents gas gradient with a density of $0.3,0.27,0.27,0.27,0.27$ and $0.27 \mathrm{~g} / \mathrm{cc}$ respectively in all wells and the second is the water gradient with a density of $1.08,1.08$, $1.1,1.06,1.14$ and $1.09 \mathrm{~g} / \mathrm{cc}$ respectively. However, the differences in the pressure values in each well indicated a lack in the lateral communication. The free water level is determined by the sudden change in gradients, it was found to be 13580, 13580, 13630, 13545, 13590 , and $13592 \mathrm{ft}$. in all wells respectively.

\section{Determination of permeability}

Geologic permeability is the ability of a substance to allow another substance to pass through it, especially the ability of a porous rock, sediment, or soil to transmit fluid through pores and cracks. It is usually measured in millidarcies. ${ }^{9}$

\section{Qualitative interpretation}

From the pressure curve the permeability of reservoir rock can be interpreted qualitatively. The pressure curve is recorded with the detected formation pressure. ${ }^{12} \Delta \mathrm{p} 1$ and $\Delta \mathrm{p} 2$ are the pressure difference during the pretest, as shown in Figure 4. The pressure difference is sensitive to the formation permeability. Generally, the greater the pressure drop required, to maintain the pretest flow rate, the lower the permeability. ${ }^{10}$ In case of high permeable interval (about $100 \mathrm{mD}$ ) neither $\Delta \mathrm{p} 1$ nor $\Delta \mathrm{p} 2$ can be shown in the record. While, in formation with lower permeability (about $10 \mathrm{mD}$ ) clearly shows the shape of the theoretical curve. Pressure curve is almost exactly the same as the theoretical curve case of $1 \mathrm{mD}$ permeability, but, the shape of the curve recorded in a very low permeability $(0.1 \mathrm{mD})$ shows no difference between the two $\Delta \mathrm{ps}$ on the analog recording. ${ }^{13}$ The qualitative permeability is nearly poor to moderate which, is about $40 \mathrm{mD}$. It is determined by applying the qualitative interpretation on the curves of the studied wells.

\section{Quantitative interpretation}

Permeability can be deduced from the flow rate measurements made with the Repeat Formation Tester (RFT) data. The permeability is deduced from the drawdown pressure in this study where, the flow inside the formation may be of different types depending on the configuration and nature of the formation. The permeability is generally considered to be spherical flow, which is acceptable in an isotropic formation, towards the packer and sampling probe.

The permeability is given by the following equation:

$$
k_{d}=5660=\frac{Q \cdot \mu}{\Delta P}
$$

Where: $\mathrm{kd}$ is the permeability deduced from drawdown

$Q$ is the flow rate in $\mathrm{cm} 3 / \mathrm{s}$

$\mu$ is the fluid viscosity in centipoise, and

$\Delta P$ is the pressure drop in (Psi) during drawdown.

This type of permeability of the pressure drop $\Delta \mathrm{P}$ deduces in the first five millimeters of the formation. ${ }^{14}$

Figure 11 shows the representation of permeability vertically for five wells. 1 to $30 \mathrm{mD}$ is the range of permeability for the considered wells which is poor to moderate permeability. Qasr-1x well is the exception in the studied wells; it shows a good permeable formation with range between $40-100 \mathrm{mD}$. Then the permeability's of the 
studied formation are nearly moderate, as deduced qualitatively and quantitatively from the (RFT) pressure curve.

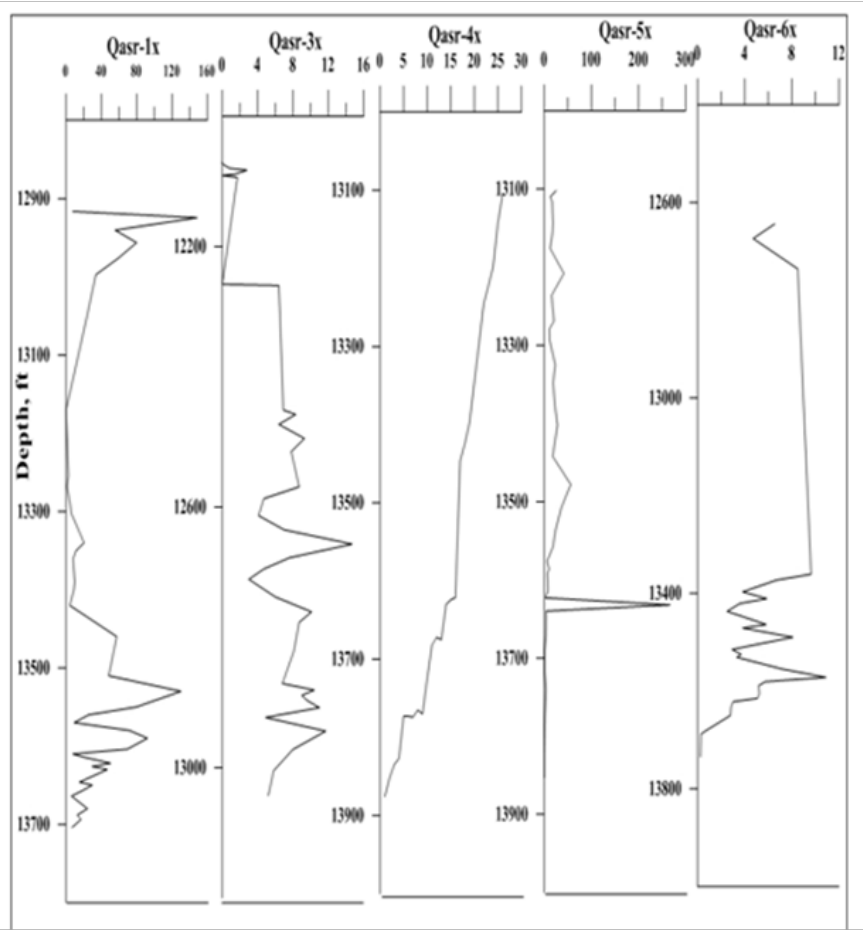

Figure I I Quantitative value of permeability deduced of dry down pressure.

\section{Summary and conclusion}

For reservoir engineering and production, the Repeat Formation Tester is an important tool. To obtain the actual formation pressure and formation permeability, RFT pressure data can be interpreted that can be applied for a better understanding of petroleum reservoirs. The application is applied on Khatatba Formation in six wells distributed in Qasr Field in the Western Desert of Egypt. The discussed application is based on the analysis of RFT pressure profiles. A pressure profile is produced by plotting formation pressures versus the true vertical depth. By evaluating the gradient of this profile, it provides information about the type of fluids and the contact between them. The values of Khatatba Formations pressure were calculated for each test and then plotted versus the depth to obtain the pressure gradients, which enable to identify the natures and densities of the gas and fluids (oil or water). Also, these measurements located the depths of contacts by monitoring the abrupt changes in the pressure gradients. The pressure profiles of Khatatba Formation in the considered wells of the studied area were constructed. The free water level is located at 13580, 13580, $1330,13545,13590$ and $13592 \mathrm{ft}$. in the studied wells respectively. The formation pressure against the depth, for Khatatba Formation in the studied wells indicates two distinct trends in the considered wells. The first gradient represents gas gradient and the second is the water gradient. In the present study, the permeability of Khatatba Formation is evaluated both qualitatively and quantitatively by using the RFT data. The qualitative evaluation of permeability includes the direct observation of the pressure curve recorded at each test. On the other hand, the quantitative assessment of permeability includes the analysis of drawdown pressure data. The qualitative and quantitative interpretation indicates that the permeability of Khatatba Formation in the studied area is mainly poor to moderate. From all the above discussion, It was recommended that, the RFT tool which indicates the present of the gas in the reservoir rock could be improved by using fracturing this formation to enhance the production of gas in the studied area.

\section{Acknowledgements}

None.

\section{Conflict of interest}

The author declares that there is no conflict of interest.

\section{References}

1. Mohamad A, Reda MA Ghorab, Shazly TF. Determination of permeability and density and nature of fluids of some Miocene-Pre Miocene rocks in the central Gulf of Suez, Egypt. Journal of Applied Geophysics. 2003;312(2):29-138.

2. Schlumberger ltd. Repeat formation tester. 1986. 14 p.

3. Salem E, Sehaim A. Structural Imaging in the East Beni Suef Basin. Northeastern Desert. Journal of African Earth Science. 20217;136:1-10.

4. Elsawy MZ. Reservoir Evaluation of the Upper Cretaceous in the North Western Desert, Egypt, Utilizing Well Log Analysis. 2102. 246 p.

5. Diasty W Sh, Beialy SY, Littke R, Farag. Source rock evaluation and nature of hydrocarbons in the Khalda Concession, Shushan Basin, Egypt's Western Desert. International journal of coal geology. 2016;162:45-60.

6. Mohsen S, Naggar A, Taher M. Geologic setting of the Western Desert during the Cretaceous time. Cairo, Egypt: Int. Report of GPC; 1973:110

7. Sultan N, Abdelhalim MA. Tectonic framework of Northern Western Desert, Egypt and its effect on hydrocarbon accumulations. EGPC 9th, Cairo. 1988;2(1):1-23.

8. Smolen JJ, Litesy LR. Formation Evaluation Using Wireline Formation Tester Pressure Data. SPE 6822, SPE 52 nd, Annual Fall Meeting, Denver Co.1977;31(1):1-8.

9. Desbrandes R. Encyclopedia of Well Logging. Houston Texas: Gulf Publishing Co; 1985.608 p.

10. Serra O. Advanced Interpretation of Wireline Logs. USA: Schlumberger Publications. 1986. 435 p.

11. Tarek F Shazly, Ahmad Z Nouh. Determination of Some Reservoir Characteristics of Bahariya Formation in Bed-1 Field, Western Desert, Egypt, By Using the Repeat Formation Tester. Petroleum Science and Technology. 2013;31:763-774.

12. Hilchie DW. Advanced Well Logging Interpretation. Golden Colorado, DW: Hilchie Environmental Septic Service; 1982. 350 p.

13. Schlumberger 1td. Log Interpretation principles and Applications. Houston, Tx: Schlumberger Educational Services; 1989. 28 p.

14. Crain ER. The Log Analysis Hand Book. USA: Penn-Well, Publ. Co; 1986. $684 \mathrm{p}$. 